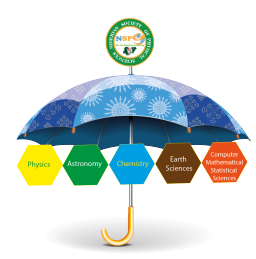

\title{
Sensitivity of Parameters in the Approach of Linear Programming to a Transportation Problem
}

\author{
Tolulope Latunde*, Joseph Oluwaseun Richard, Opeyemi Odunayo Esan, Damilola Deborah Dare \\ Department of Mathematics, Federal University, Oye-Ekiti, Nigeria
}

\begin{abstract}
Linear programming has served as a great tool in dealing with transportation problems to make a positive difference in economic and social activity. In this work, data of the National Union Of Road Transport Workers (NURTW) is analysed to minimizing the cost of maintenance and repair of buses taking the route from Sango park to different routes. Data collected from the park are represented using tables and solved using the Maple computer software application. The transportation problem is solved such that the transportation cost is minimized which leads to the profit being maximized. This is achieved by estimating the values of some identified parameters in the problem. This work will be beneficial to every other motor parks controllers to decide on some decision making that may bring to the union profit. This work will help the NURTW in Sango to spend less on the vehicles and save more as income.
\end{abstract}

Keywords: Linear Programming, transportation problem, parameters, sensitivity

Article History :

Received: 26 September 2019

Received in revised form: 26 October 2019

Accepted for publication: 29 October 2019

Published: 12 November 2019

(c)2019 Journal of the Nigerian Society of Physical Sciences. All rights reserved. Communicated by: B. J. Falaye

\section{Introduction}

One major problem encountered by companies or organizations is the transportation problem. The transportation problem was given shape as a problem in 1871 by a French economist and mathematician called Gaspard Monge, the transportation problem was first studied in 1920 as a problem by Aleskey Nikolayevich, [1].

Here, we study the Sango NURTW which runs the transport service both in Ogun State and outside the state. Since the transportation problem is to find a way of minimizing cost (or time spent) or to maximize profit, the goal of every transportation is to meet the request of the destination.

\footnotetext{
*Corresponding author tel. no: +2348032801624

Email address: tolulope. latunde@fuoye.edu.ng (Tolulope Latunde)
}

In this study, we only have two destinations, one destination is seen from the other, they are respectively the place where the vehicles will stop eventually when it leaves the park and the park itself. The optimization of transportation problem can apply to so many areas like the Genetic Algorithm, Networking, Modelling and many more.

The transportation method in use is a type of linear programming problem that utilises the simplex technique. It is applied to the problems related to the study of the efficient transportation routes i.e., how efficiently the product from different sources of production is transported to the different destination such as the total transportation cost is minimum.

Here, we revise the solution of the formulated transportation problem until the optimum solution is obtained, thus we varied the values of parameters in the model to study the behaviours of each parameter of the model. 
Since usually the objective of the transportation problem is to either minimize the distance to be covered, total transportation cost or to maximize profit. The transportation problem can be defined mathematically as; suppose $X_{i j} \geq 0$ is the number of passengers traveling from $i t h$ origin to the $j t h$ destination the model of the problem given the cost of transportation $c$ will be,

$$
\begin{array}{r}
\text { Minimize } \mathrm{Z}=\sum_{i=1}^{m} \sum_{j=1}^{n} c_{i j} X_{i j} \\
\text { Subject to } \sum_{j=1}^{n} X_{i j} \leq a_{i} \text { for } i=1,2, \ldots, m \text { i.e supply } \\
\sum_{i=1}^{m} X_{i j} \leq b_{j} \text { for } j=1,2, \ldots, n \text { i.e demand. } \\
\forall X_{i j} \geq 0
\end{array}
$$

If $\sum_{i=1}^{n} a_{i}=\sum_{j=1}^{n} b_{j}$, this means that the number of passengers available is equal to the number of available spaces in the vehicles to transport them. If not, it will be considered unbalanced transportation in this work.

\section{Literature Review}

In recent times, books have been written, papers published and presentation made diversely on the transportation problem, we generally that in a layman language, the transportation problem is one of the optimization problems.

A new way of solving the transportation problem from the park to different destinations was introduced in [2], the method used was readers friendly, easily accessible and can be quickly understood. The last table can be used to decipher the roads that serve as the best to be plied as well it explains the roads that need more vehicles to be added to increase the income rate.

The cost coefficient of the objective function was dealt with thoroughly seeing into the multi-objective problems of transportation in [3]. A minimization work from the origin to the destination was carried out. The fuzzy programming technique was utilized to solve the problem that was converted from constraints to a deterministic solvable problem.

Asase did a great work on the transportation problem also, he used the GUINNESS GHANA LIMITED in Kumasi as a case study, he explained the transportation problem, created a table and solved using the Vogel, North-West Corner, Least Cost method as well as for test for optimality, he used the Stepping Stone method and the Modified Distribution Method (MODI) [4].

A k-objective transportation problem was formulated in [5] by fuzzy numbers and used alpha-cut to obtain a transportation problem in the fuzzy sense expressed in linear programming form. An additive fuzzy programming model for the multiobjective transportation problem was introduced. The method aggregates the membership functions of the objectives to construct the relevant decision function. Weights and priorities for non-equivalent objectives are also incorporated in the method.
Their model gave a non-dominated solution which is nearer to the best-compromised solution.

In the paper - Optimal Solution of a Transportation Problem, a method was developed in [6] to get the initial basic feasible solution (or near to the optimal solution) of transportation problem. Also, the algorithm provided in this paper gives the idea for the optimality in comparison with MODI method as the flow of steps by step procedure. The paper helps in explaining vividly the Algorithm used, the test of optimality and numerous numerical examples.

However, some researchers have worked in the areas of sensitivity analysis and its application to transportation. Parameter estimation and sensitivity analysis of an optimal control model for capital asset management where the parameters of the formulated model of asset management are classified according to their degree of sensitivity was worked on in [7]. Also, the sensitivity of parameters in an optimal control model of the electric power generating system to determine the behaviour of the model's parameters in [8]. Pandian and Kavitha proposed a new bound technique for cost sensitivity ranges of solid transportation problems [9].

In this work, the MAPLE software is used to derive the expected income and also determine the best routes that needed to be invested in the most by analysing the sensitivity of the parameters involved in the model.

\section{Statement of problem}

Given that some passengers are to travel to different destinations from an NURTW transport company, there is a need for the NURTW to optimize the cost of transportation, determine the best ways of allocating vehicles by either increasing or decreasing the number of vehicles on a particular route.

The total cost of transporting the passengers from the park $i$ to the destination $j$ is not changing from every other transportation problem. This is given by letting $i=$ park and then $j=$ destinations, prior $a_{i}$ and $b_{j}$ above $x_{i j}$ is the number of passengers to be transported from Sango park i to the different destinations:

$$
\sum_{j=1}^{n} c_{i j} x_{i j}=c_{11} x_{11}+c_{12} x_{12}+\ldots+c_{1 n} x_{1 n}
$$

The total cost $T_{c}$ of transporting the passengers from Sango park to the different destinations.

$$
\begin{array}{r}
T_{c}=\sum_{i=1}^{m} \sum_{j=1}^{n} c_{i j} x_{i j} \\
=c_{11} x_{11}+c_{12} x_{12}+\ldots+c_{1 n} x_{1 n} \\
c_{21} x_{21}+c_{22} x_{22}+\ldots+c_{2 n} x_{2 n} \\
. \\
c_{m 1} x_{m 1}+c_{m 2} x_{m 2}+\ldots+c_{m n} x_{m n}
\end{array}
$$


The NURTW agrees generally in Sango to offer services of transporting her passengers from Sango both intra-state and interstate as listed below.

\author{
Intra-State \\ Sango-Atan \\ Sango-Ewekoro \\ Sango-Ifo \\ Sango-Owode \\ Sango-Idi-Iroko \\ Sango-Abeokuta \\ Sango-Ijebu Ode \\ Sango-Ijebu Remo \\ Sango-iperu \\ Inter-State \\ Sango-Lagos (Ikeja) \\ Sango-Ondo (Akure) \\ Sango-Oyo (Ibadan) \\ Sango-Osun (Oshogbo) \\ Sango-Ekiti (Ado-Ekiti)
}

\section{Data Collation and Analysis}

All data were gotten from Sango park in March 2019 at Sango, Ogun State. Data were gotten by conversation and interviewing one of the Sango NURTW official staff. The Destination: This is the destination the vehicles go to from the park. It is the place the passengers paid for a service to be delivered to them.

The Trip: This is the to and fro movement a vehicle completes weekly. We should note that daily means all the vehicles can travel every day, turn means it depends on the total number of vehicles available and it is determined by how early the vehicles arrive as they will leave respectively as they have come.

Fuel: This is the average amount of fuel consumption (in litres) per trip.

B/Rt: (Buses per route)These are the number of buses the NURTW for Sango agreed to travel in a day.

Hrs/trip: This is the total number of hours it takes a vehicle to travel to the destination and to travel back to the park if it leaves immediately.

T. fare: The T.fare here means transportation fare. In essence, it is the cost a passenger is charged for transportation service, better explained as the transportation fare per person in Naira N.

Table 2 is an average data from different distributors, hence it might be a little bit expensive or cheaper depending on the bargaining power.

In Table 3, public drivers and Sango NURTW mode of servicing their vehicles differ. The road differs, some are bad, some are fair and others are good, on that basis, some drivers will have to service their vehicles fortnightly, some every week and most service their vehicles monthly. This implies that a vehicle will get serviced at the rate of $\mathbf{N} 8700$ per month implying that averagely a vehicle will be serviced for $\mathbf{N} 256.7$ daily.

We carefully noticed that the analysis above in Table 4 is not true for all route, as stated earlier above, some route may cost more as some roads are bad e.g the Sango to Owode-Iroko, this road attracts twice the amount most times.

Fuel : This is gotten by the litres of fuel used in a trip, as at the time of this thesis, a litre is $\mathbf{N} 145$, therefore, the fuel consumption cost is the total number of litres multiply by 145 in (Naira).

Parking Charges : This is the amount a vehicle driver will pay at the garage of the destination, this is because NURTW, Sango does not have a parking space of her own.

B/Trp : This short form for Bus Per Trip. It is the number of buses per trip that can be on the road at a time.

Hrs/trip : This is the short form for Hours Per Trip. The time taken for a bus to reach the destination and fro.

CVS/day : This is the short form for Cost of Vehicle Service Per day.

VRM/day : This is the short form for Vehicle Repair and Maintenance Per day.

Income/trip : This is gotten by multiplication of the transport fare twice, twice because a trip is to and fro then multiplied by the number of people in a bus. The total number of passengers in a bus is 14 i.e (TFare $\times 2 \times 14)$,

Expense/day : This is gotten from adding the Fuel Consumption Cost + the Parking Charges + Servicing Vehicles Cost Per Day + Vehicles Maintenance Per Day.

Income/day : This is gotten from subtracting Vehicles Expense Per Day from Income for a Trip per day.

Parking Charges : This is the multiplication of the amount of Parking charges per Bus by the number of buses per on the road at a time.

Fuel : This is the multiplication of fuel used in a trip by the number of buses on the road at a time (B/Trp).

CVS : This is the cost vehicle service multiplied by $\mathbf{B} / \mathbf{R t}$

VRM : This is the cost of vehicles repair and maintenance multiplied by $\mathbf{B} / \mathbf{R t}$,

Income/Trip : This is gotten by multiplying the income per trip of the bus by the total number of buses that can be on the road at a time.

Total Expense : This is the sum of by Parking Charges, Amount of Fuel used, CVS and VRM.

Total Income : This is the difference between Income/Trip and the Total Expense.

\section{Model Description}

The formulation of the problem is based on data gotten from the park and the immediate Table 5. NURTW (SANGO PARK) allows the maximum of 140 buses in total to travel the road to all road to these respective destinations every day. Meanwhile, these buses can be assigned to leave the park.

Solving the above linear programming problem, we derive N1,069,345.7. However, our goal in this work is to sensitize each parameter of the model to derive optimal allocation. Thus from Table 6, we increase all routes in twos respectively from the Atan destination to the Ekiti destination, we keep repeating this process for all the routes till 10 buses are added to all the routes. 
Table 1: Data on Trips

\begin{tabular}{|l|l|l|l|l|l|l|}
\hline S/N & Destination & Trip(Weekly) & Fuel(Ltrs) & B/Rt & Hrs/trip & T. Fare N \\
\hline 1 & Atan & Daily & 15 & 20 & 1 & 150 \\
2 & Ewekoro & Daily & 15 & 20 & 1 & 200 \\
3 & Ifo & Daily & 20 & 15 & 1.5 & 300 \\
4 & Owode & Daily & 15 & 20 & 1.5 & 300 \\
5 & Idiroko & Daily & 25 & 10 & 2 & 400 \\
6 & Abeokuta & Turn & 30 & 10 & 2.5 & 500 \\
7 & Ijebu-Ode & Thrice & 70 & 3 & 5 & 1500 \\
8 & Ijebu-Remo & Thrice & 75 & 3 & 6 & 1700 \\
9 & Iperu & Thrice & 75 & 3 & 6 & 1800 \\
10 & Lagos & Daily & 20 & 15 & 2 & 300 \\
11 & Ondo & Five Times & 35 & 7 & 3 & 700 \\
12 & Oyo & Turn & 70 & 2 & 4 & 1150 \\
13 & Osun & Turn & 85 & 2 & 5.5 & 2300 \\
14 & Ekiti & Turn & 95 & 2 & 7 & 2550 \\
\hline
\end{tabular}

Table 2: Data On Vehicle Repair and Maintenance (VRM)

\begin{tabular}{|c|c|c|c|}
\hline S/N & ITEM & COST & DURABILITY \\
\hline 1 & Break disk & 10500 & 2 years \\
2 & Break lining & 3000 & 1 months \\
3 & Break Pad & 1800 & 3 weeks \\
4 & Car battery & 15000 & 2 years \\
5 & Front bearing & 7000 & 5 months \\
6 & Fuel pump & 5500 & 2 years \\
7 & Release bearing & 3000 & 2 years \\
8 & Shock absorber & 11000 & 2 years \\
9 & Shock filling & 1800 & 6 months \\
10 & Tyre & 24000 & 4 months \\
\hline & Total & 82,600 & \\
\hline
\end{tabular}

Table 3: Cost Of Vehicle Service (CVS)

\begin{tabular}{|l|l|l|l|}
\hline S/N & Service Item & Amount Monthly & Cost Per Day \\
\hline 1 & Engine Oil (5ltrs) & 5000 & 166.7 \\
2 & Oil filter & 1700 & 56.7 \\
3 & Oil treatment & 650 & 33.3 \\
\hline & Total & 8700 & 256.7 \\
\hline
\end{tabular}

We then run every addition by the Maple software to ascertain the outcome and to determine the profit that will be generated, it was noticed that some routes yielded more income than the others as the buses plying the routes were increased.

Table 7 represents the optimal result of the formulated model.

Bus: This is the representation of each route respectively from the Atan destination being $\mathbf{X} \mathbf{1}$ to the last destination i.e Ekiti represented as X14.

Total No of Buses: This is the new total number of buses assumed to be on the road at once from Sango park.

Former B/Rt : (Former Buses per route) This is the total number of buses plying a particular at once before the increase.
New B/Rt: (New Buses per route) This is the total number of buses plying a particular at once after the increase.

Income Generated: This is the result compiled by the Maple software after the buses have been respectively increased in Naira $\mathbf{N}$.

It is important to note that when none of the bus plying the route was increased, the income generated remains the same as the income generated in Table 6 i.e N1,069,345.7. The highest income generated is from X14 which is the Ekiti destination producing $\mathbf{N} 1,617,172.7$.

\subsection{Discussion on Result}

Table 8 shows our recommendation as to know which the routes needs increment of more vehicle to ply them and the outcome of our result is represented in Figure 1 where it can be interpreted on the graph to see that the income generated by the $\mathbf{X 1 4}$ being the Ekiti destination yields the highest income.

Figure 1 below shows the income generated by every bus. The buses are labelled respectively from the Atan destination as X1 to Ekiti as X14. The bus that generated the highest income is the X14, the bus plying Ekiti. The problem was solved in Maple software and represented in Table 8 and Figure 1 whereby the optimal value of N1,617,172.7 is obtained instead of the N1,069,345.7 after selecting the optimal allocation of vehicles to best routes by sensitising the parameters of the model. However, to determine the optimal vehicle allocation, we varied the values of parameters representing each vehicle in the model with respect to its location to understand how each parameter behaves.

Thus we recommend that Ekiti routes should get more buses to ply it to optimize the cost transportation. This will yield extra N 547,827 more as profit.

\section{Conclusion}

Due to some uncertainties in the cost of VRM, CVS and some other input parameters, non-linear constraint optimization problem shall be considered in future works to tackle this. 
Table 4: Cost Of Vehicle Repair and Maintenance Per Day

\begin{tabular}{|l|l|l|l|c|l|}
\hline S/N & Item & Item cost & Durability & Durability (Day) & Cost (Day) \\
\hline 1 & Break disk & 10500 & 2 years & 720 & 14.6 \\
2 & Break lining & 3000 & 1 months & 30 & 100 \\
3 & Break Pad & 1800 & 3 weeks & 21 & 85.7 \\
4 & Car battery & 15000 & 2 years & 720 & 20.8 \\
5 & Front bearing & 7000 & 5 months & 150 & 46.7 \\
6 & Fuel pump & 5500 & 2 years & 720 & 7.6 \\
7 & Release bearing & 3000 & 2 years & 720 & 4.2 \\
8 & Shock absorber & 11000 & 2 years & 720 & 15.3 \\
9 & Shock filling & 1800 & 6 months & 180 & 10 \\
10 & Tyre & 24000 & 4 months & 48 & 500 \\
\hline & Total & 82,600 & & & 804.9 \\
\hline
\end{tabular}

Table 5: Total Income per day

\begin{tabular}{|c|c|c|c|c|c|c|c|c|c|c|c|}
\hline $\mathrm{S} / \mathrm{N}$ & Fuel(Ltrs) & Fuel N & Parking charges $\mathbf{N}$ & $\mathrm{B} / \operatorname{Trp}$ & Hrs/trip & T.Fare $\mathbf{N}$ & CVS/day $\mathbf{N}$ & VRM/day $\mathbf{N}$ & Income/trip $\mathbf{N}$ & Expense/day $\mathbf{N}$ & Income/day $\mathbf{N}$ \\
\hline 1 & 15 & 2175 & 0 & 20 & 1 & 150 & 256.7 & 804.9 & 4200 & 3236.6 & 963.4 \\
\hline 2 & 15 & 2175 & 0 & 20 & 1 & 200 & 256.7 & 804.9 & 5600 & 3236.6 & 2363.4 \\
\hline 3 & 15 & 2900 & 0 & 15 & 1.5 & 300 & 256.7 & 804.9 & 8400 & 3169.6 & 4438.4 \\
\hline 4 & 15 & 2175 & 0 & 20 & 1.5 & 300 & 256.7 & 804.9 & 1609.8 & 4041.5 & 4358.5 \\
\hline 5 & 25 & 3625 & 0 & 10 & 2 & 400 & 256.7 & 1609.8 & 11200 & 5491.5 & 5708.5 \\
\hline 6 & 30 & 4350 & 150 & 10 & 2.5 & 500 & 256.7 & 804.9 & 14000 & 5561.6 & 8438.4 \\
\hline 7 & 70 & 10150 & 350 & 3 & 6 & 1500 & 256.7 & 1609.8 & 42000 & 12366.6 & 29633.5 \\
\hline 8 & 75 & 10875 & 350 & 3 & 6 & 1700 & 256.7 & 1609.8 & 47600 & 13091.5 & 34508.5 \\
\hline 9 & 75 & 10875 & 300 & 3 & 6 & 1800 & 256.7 & 804.9 & 50400 & 12236.6 & 38163.4 \\
\hline 10 & 20 & 2900 & 0 & 15 & 2 & 300 & 256.7 & 804.9 & 8400 & 3961.6 & 4438.4 \\
\hline 11 & 35 & 5075 & 200 & 7 & 3 & 700 & 256.7 & 1609.8 & 19600 & 7141.5 & 12458.5 \\
\hline 12 & 70 & 10150 & 300 & 2 & 4 & 1150 & 256.7 & 1609.8 & 32200 & 12316.5 & 198835 \\
\hline 13 & 85 & 12325 & 350 & 2 & 5.5 & 2300 & 256.7 & 1609.8 & 64400 & 14541.5 & 49855.5 \\
\hline 14 & 95 & 13775 & 350 & 2 & 7 & 2550 & 256.7 & 2414.7 & 71400 & 16796.4 & 54603.6 \\
\hline Total & 645 & 93525 & 2350 & & & 13850 & 3593.8 & 18507.7 & 387800 & 103454.54 & 269815.5 \\
\hline
\end{tabular}

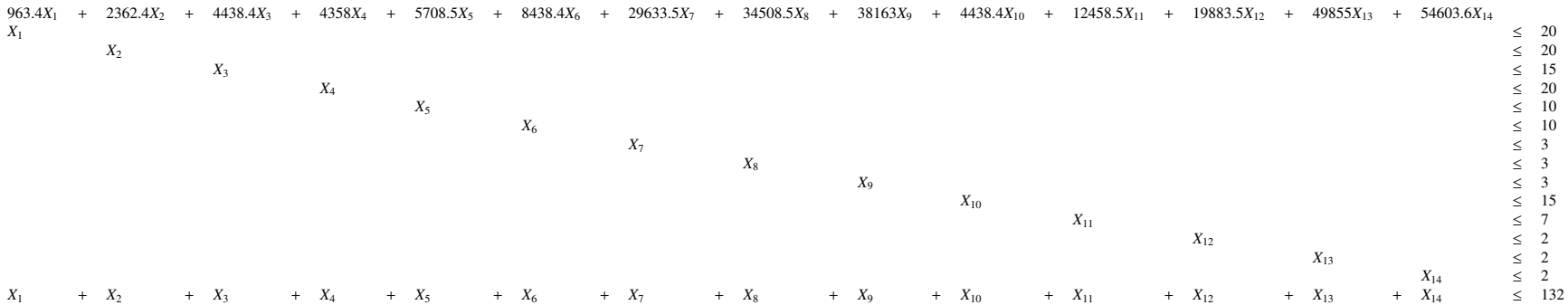

Table 6: The total income of all buses on the road at a time

\begin{tabular}{|c|c|c|c|c|c|c|c|c|c|c|}
\hline S/N & Dest. & Parking Charges N & B/Rt & Fuel & T.Fare N & CVS N & VRM N & Income/Trip N & Total Expense N & Total Income N \\
\hline 1 & Atan & 0 & 20 & 43500 & 3000 & 5134 & 16098 & 84000 & 64732 & 19268 \\
2 & Ewekoro & 0 & 20 & 43500 & 4000 & 5134 & 16098 & 112000 & 64732 \\
3 & Ifo & 0 & 15 & 43500 & 4500 & 3850.5 & 12073.5 & 126000 & 59424 \\
4 & Owode & 0 & 20 & 43500 & 6000 & 5134 & 3219.6 & 168000 & 80830 \\
5 & Idiroko & 0 & 10 & 36250 & 4000 & 2567 & 16098 & 112000 & 54915 \\
6 & Abeokuta & 1500 & 10 & 43500 & 5000 & 2567 & 8049 & 140000 & 55616 \\
7 & Ijebu-Ode & 1050 & 3 & 30450 & 4500 & 770.1 & 4829.4 & 126000 & 39274.5 \\
8 & Ijebu-Remo & 1050 & 3 & 32625 & 5100 & 770.1 & 4829.4 & 141000 & 37099.5 & 87.5 \\
9 & Iperu & 900 & 3 & 32625 & 5400 & 770.1 & 2414.7 & 151200 & 36708 & 88900.5 \\
10 & Lagos & 0 & 15 & 43500 & 4500 & 3850.5 & 12073.5 & 126000 & 59424 & 114492 \\
11 & Ondo & 1400 & 7 & 35525 & 4900 & 1796.9 & 11268.6 & 137200 & 49990.5 & 87209 \\
12 & Oyo & 600 & 2 & 20300 & 2300 & 513.4 & 3219.6 & 64800 & 24633 \\
13 & Osun & 700 & 2 & 24550 & 4600 & 513.4 & 3219.6 & 128800 & 29083 \\
14 & Ekiti & 70 & 2 & 27550 & 5100 & 513.4 & 4828 & 142800 & 33592.8 & 39767 \\
\hline & Total & 7900 & 132 & 455875 & 62900 & 33884.4 & 118318.9 & 17579400 & 690054.3 & 109717 \\
\end{tabular}


Table 7: Result of Sensitivity analysis analysis on the model

\begin{tabular}{|l|l|c|c|c|c|}
\hline S/N & Bus & Total No of Buses & Former B/Rt & New B/Rt & Income Generated N \\
\hline 1 & X1 & 142 & 20 & 30 & $1,080,770.7$ \\
2 & X2 & 142 & 20 & 30 & $1,115,520.7$ \\
3 & X3 & 142 & 15 & 25 & $1,115,520.7$ \\
4 & $\mathbf{X 4}$ & 142 & 20 & 30 & $1,114,721.7$ \\
5 & $\mathbf{X 5}$ & 142 & 10 & 20 & $1,128,221.7$ \\
6 & $\mathbf{X 6}$ & 142 & 10 & 20 & $1,155,520.7$ \\
7 & $\mathbf{X 7}$ & 142 & 3 & 13 & $1,367,471.7$ \\
8 & $\mathbf{X 8}$ & 142 & 3 & 13 & $1,416,221.7$ \\
9 & $\mathbf{X 9}$ & 142 & 3 & 13 & $1,452,766.7$ \\
10 & $\mathbf{X 1 0}$ & 142 & 15 & 25 & $1,115,520.7$ \\
11 & $\mathbf{X 1 1}$ & 142 & 7 & 17 & $1,195,721.7$ \\
12 & $\mathbf{X 1 2}$ & 142 & 2 & 12 & $1,269,971.7$ \\
13 & $\mathbf{X 1 3}$ & 142 & 2 & 12 & $1,569,691.7$ \\
14 & $\mathbf{X 1 4}$ & 142 & 2 & 12 & $1,617172.7$ \\
\hline
\end{tabular}

Table 8: Optimal allocation based on sensitivity of the parameters

\begin{tabular}{|l|l|c|c|}
\hline S/N & Destination & Former B/Rt & Recommend B/Rt \\
\hline 1 & Atan & 20 & 20 \\
2 & Ewekoro & 20 & 20 \\
3 & Ifo & 15 & 15 \\
4 & Owode & 20 & 20 \\
5 & Idiroko & 10 & 10 \\
6 & Abeokuta & 10 & 10 \\
7 & Ijebu-Ode & 3 & 3 \\
8 & Ijebu-Remo & 3 & 3 \\
9 & Iperu & 3 & 3 \\
10 & Lagos & 15 & 15 \\
11 & Ondo & 7 & 7 \\
12 & Oyo & 2 & 2 \\
13 & Osun & 2 & 2 \\
14 & Ekiti & 2 & 12 \\
\hline
\end{tabular}

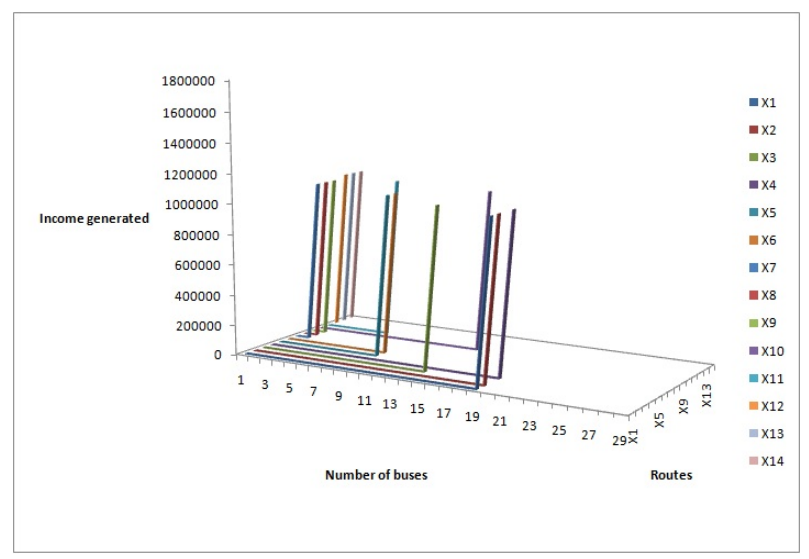

Figure 1: The Graph of Income generated against number of buses by routes
However, as a result of sensitivity analysis carried on the param-

eters of the formulated model, we recommend that additional buses should be considered to the best route of Sango-Ekiti to optimize income and minimize cost.

\section{References}

[1] S. Sarbjit, "Note on Transportation Problem with New Method for Resolution of Degeneracy", Universal Journal of Industrial and Business Management, 3(2012) 26.

[2] N. Ngutor, J. O Omolehin \& K. Rauf, "Application of Linear programming in Modeling the Allocation of Buses to Routes in a Transport Service Authority", Universal Journal of Applied Mathematics, 2 (2014) 125.

[3] J. C. Das, Load Flow Optimization and Optimal Power Flow, Boca Raton: CRC Press, 2017.

[4] A. Asase, The Transportation Problem, Case study: Guiness Ghana Limited", Master's Thesis, Faculty of Physical Science and Technology Kumasi, Ghana, 2011.

[5] A. K. Bit, M. P. Biswal \& S. S. Alam, "Fuzzy Programming Approach to Multicriteria Decision making Transportation problem", Fuzzy sets and systems, 5 (1992) 135.

[6] R. G. Patel, B. S. Patel \& P. H. Bhathwala, "On Optimal Solution of a Transportation Problem", Global Journal of Pure and Applied Mathematics, 13 (2017) 6201.

[7] T. Latunde \& O. M. Bamigbola, "Parameter Estimation and Sensitivity Analysis of an Optimal Control Model for Capital Asset Management", Advances in Fuzzy Systems https//doi.org/10.1155/2018/4756520

[8] T. Latunde, O. M. Bamigbola \& Y. O. Aderinto, "Sensitivity of Parameters in an Optimal Control Model of the Electric Power Generating System", Ilorin Journal of Computer Science and Information Technology (ILJCSIT), 1 (2016) 54.

[9] P. Pandian \& K. Kavitha, "Sensitivity Analysis in Solid Transportation Problems”, Applied Mathematical Sciences,6 (2012) 6787. 